\title{
Evaluation of antioxidant activities of extracts from 19 Chinese edible flowers
}

Youwei Zeng ${ }^{1}$, Maocheng Deng ${ }^{1,2}$, Zhencheng LV ${ }^{3}$ and Yonghong Peng ${ }^{3,4^{*}}$

\begin{abstract}
Extracts of 19 selected edible flowers were investigated for their free radical scavenging activity (FRSA), polyphenolic contents and flavonoid contents in the paper. The results showed the extracts of Paeonia suffruticosa Andr., Paeonia lactiflora Pall., and Rosa rugosa Thunb. possessed obviously stronger DPPH FRSA (94.221 \pm 0.102 ; $93.739 \pm 0.424$ and $94.244 \pm 0.163 \%$, respectively), superoxide FRSA $(55.818 \pm 1.518 ; 52.142 \pm 1.374$ and $57.321 \pm$ $0.608 \%$, respectively), hydroxyl FRSA $(85.872 \pm 0.873 ; 89.307 \pm 0.803$ and $88.560 \pm 0.277 \%$, respectively) and polyphenolic contents ( $96.208 \pm 0.689 ; 87.938 \pm 1.187$ and $92.164 \pm 0.799 \mathrm{mg}$ CE/g, respectively) that were superior or comparable to black and green teas. Polyphenolic contents did correlate well with DPPH FRSA $(r=0.943$, $P<0.01)$, superoxide FRSA $(r=0.833, P<0.01)$, and hydroxyl FRSA $(r=0.500, P<0.05)$. It indicated that this potent FRSA may be attributed to its phenolic compounds. These findings showed that the tested flowers could be considered as new sources of safe natural antioxidants and preservatives of food industry.
\end{abstract}

Keywords: Edible flowers; Extracts; Free radical scavenging activity; Polyphenolic content; Flavonoid content

\section{Introduction}

Roles of the reactive oxygen species (ROS) and free radicals such as superoxide anion radicals, hydrogen peroxide and hydroxyl radicals are increasingly recognized in physiological process, and pathogenesis of many diseases (Moskovitz et al. 2002; Balaban et al. 2005). Their action is opposed by a balanced system of antioxidant defense, and excessive amount of ROS can initiate toxic and lethal chain reactions, which leads to cell damage and health problems (Aruoma 1998; Saeidnia and Abdollahi 2013). Recently, there is a growing interest in substances from natural sources exhibiting antioxidant properties that can be used to protect human beings from oxidative stress damage (Kris-Etherton et al. 2002). Substantive experiments have been focused on the phytochemicals and extracts from plants sources possessing antioxidant effects. Reports indicate that there is an inverse relationship between the dietary intake of antioxidant-rich plant source foods and the incidence of human disease

\footnotetext{
* Correspondence: pengyh@scnu.edu.cn

${ }^{3}$ Department of Life Science, Huizhou University, Huizhou 516007, Guangdong, China

${ }^{4}$ College of Life Science, Guangdong Key Lab of Biotechnology for Plant Development, South China Normal University, Guangzhou 510631, Guangdong, China

Full list of author information is available at the end of the article
}

(Sies 1993). However, many synthetic antioxidants such as butylated hydroxytoluene (BHT) and butylated hydroxyanisole (BHA) are widely used as food additives and may be responsible for liver damage and carcinogenesis (Williams et al. 1999).

Therefore, the development and utilization of more effective and non-toxic antioxidants from natural products are desired, not only for the food and drug storage, but also for the nutritional and clinical applications. A great deal of effort has focused on using available experimental techniques to identify natural antioxidants from medicinal plants (André et al. 2010). It is well known that the traditional Chinese herbs have been used in food and medicine over two thousand years (Wang et al. 2012). Those herbs may contain a wide variety of chemical composition, including phenolic compounds (e.g. phenolic acids, flavonoids, quinones, coumarins, lignans, stilbenes, tannins), nitrogen compounds (including alkaloids), vitamins, terpenoids (including carotenoids), with potential antioxidant activities (Cai et al. 2006). It showed herbs possessing anti-inflammatory, antiatherosclerotic, hypolipidemic, antiplatelet, antitumor, or immune-stimulating properties might be proper candidates to help reduce the risk of cardiovascular disease and cancer (Krishnaiah et al. 2011).

\section{实 Springer}


Edible herbal resources can provide enormous scope in correcting the imbalance through regular intake of proper diet. The objectives of this study is to survey the free radical scavenging activity (FRSA), total phenolic contents and total flavonoid contents of 19 selected species that are very popular as herbal flower teas in China, with comparisons with black and green teas of Camellia sinensis carried out as positive controls, in view of their potential benefits of natural antioxidants for food and medicinal purposes.

\section{Materials and methods \\ Materials}

Herbal flowers, together with black and green teas of $C$. sinensis, screened for FRSA are listed in Table 1. The dried herbal flowers were purchased form Yuyi Co., Ltd. Shanghai, black and green teas were Lipton products Unilever, and their origins were identified and proved by the College of Life Science South China Normal University. The flowers were dried, and then ground into fine particles with a special grinder for food processing. Sample $(2.00 \mathrm{~g})$ was suspended and extracted by refluxing with $50 \mathrm{ml}$ boiling distilled water for $30 \mathrm{~min}$. After cooling the extracts were filtered through a filter paper and the filtrates were freeze-dried. Analyses of aqueous extracts were done in triplicate. The dried extracts were diluted to a contraction of $1 \mathrm{mg} / \mathrm{ml}$ and stored at $4^{\circ} \mathrm{C}$ for further analysis.

\section{DPPH free radical scavenging assay}

Effects of extracts on $\mathrm{DPPH}^{*}$ based on the method modified by Sharma and Bhat (2009). $0.1 \mathrm{ml}$ of aqueous extract was added to $2.4 \mathrm{ml}$ of $0.12 \mathrm{mM} \mathrm{DPPH}^{*}$ solution and the mixture was shaken vigorously, after incubation at $25^{\circ} \mathrm{C}$ for $30 \mathrm{~min}$, the absorbance was read at $517 \mathrm{~nm}$ against a blank of $50 \%$ ethanol using a Shimadzu UV1206 ultraviolet-visible spectrophotometer (Shimadzu, Japan). The free radical scavenging activity (FRSA) was calculated using the following equation:

$$
\operatorname{FRSA}(\%)=\left[\left(\mathrm{A}_{\text {blank }}-\mathrm{A}_{\text {sample }}\right) / \mathrm{A}_{\text {blank }}\right] \times 100
$$

Where $A_{b l a n k}$ is the absorbance of the control reaction (containing all of the reagents except the test extract) and $\mathrm{A}_{\text {sample }}$ is the absorbance of the test samples. Each assay was performed in triplicate.

Table 1 Free radical scavenging activities of various herbal flowers and their polyphenolic contents and flavonoid contents $^{\mathrm{a}}$

\begin{tabular}{|c|c|c|c|c|c|}
\hline \multirow{2}{*}{ Plant names } & \multicolumn{3}{|c|}{ FRSA (\%) } & \multirow{2}{*}{$\mathrm{PC}(\mathrm{mg} \mathrm{CE} / \mathrm{g})$} & \multirow{2}{*}{$\mathrm{FC}(\mathrm{mg} \mathrm{CE} / \mathrm{g})$} \\
\hline & $\mathrm{DPPH}^{\circ}$ & $\mathrm{OH}$ & $\mathrm{O} \cdot \frac{-}{2}$ & & \\
\hline Chrysanthemum indicum $\mathrm{L}$. & $14.125 \pm 0.313$ & $54.450 \pm 1.539$ & $18.538 \pm 0.413$ & $13.043 \pm 0.315$ & $44.629 \pm 0.921$ \\
\hline Chrysanthemum morifolium Ramat & $11.970 \pm 0.296$ & $33.513 \pm 0.844$ & $0.431 \pm 0.116$ & $5.974 \pm 0.148$ & $10.837 \pm 0.336$ \\
\hline Dianthus carryophylus L. & $13.528 \pm 0.651$ & $43.488 \pm 1.610$ & $5.058 \pm 1.152$ & $6.835 \pm 0.449$ & $53.248 \pm 0.091$ \\
\hline Hibiscus sabdariffa Linn. & $18.916 \pm 0.732$ & $93.220 \pm 0.346$ & $21.723 \pm 1.325$ & $8.296 \pm 0.293$ & $24.469 \pm 0.444$ \\
\hline Jasminum sambac (L.) Ait. & $13.047 \pm 0.576$ & $78.375 \pm 0.656$ & $0.405 \pm 0.268$ & $10.174 \pm 0.230$ & $54.357 \pm 0.319$ \\
\hline Lavandula angustifolia Mill. & $47.213 \pm 0.373$ & $67.055 \pm 1.685$ & $40.290 \pm 2.033$ & $20.426 \pm 0.499$ & $27.392 \pm 1.421$ \\
\hline Lilium longiflorum Thumb. & $13.987 \pm 0.363$ & $84.737 \pm 0.235$ & $15.124 \pm 0.774$ & $1.070 \pm 0.148$ & $22.123 \pm 0.168$ \\
\hline Lonicera japonica Thunb. & $50.789 \pm 1.307$ & $60.842 \pm 1.584$ & $42.277 \pm 0.704$ & $32.113 \pm 1.126$ & $34.112 \pm 0.543$ \\
\hline Matthiola incana (L.) R. Br. & $19.284 \pm 0.304$ & $78.973 \pm 1.438$ & $1.802 \pm 0.989$ & $7.069 \pm 0.148$ & $36.672 \pm 0.277$ \\
\hline Osmanthus fragrans (Thunb.) Lour. & $54.963 \pm 0.596$ & $52.210 \pm 0.695$ & $58.420 \pm 0.842$ & $47.452 \pm 1.855$ & $20.373 \pm 0.241$ \\
\hline Paeonia lactiflora Pall. & $93.739 \pm 0.424$ & $85.872 \pm 0.873$ & $55.818 \pm 1.518$ & $87.938 \pm 1.187$ & $28.757 \pm 0.419$ \\
\hline Paeonia suffruticosa Andr. & $94.221 \pm 0.102$ & $89.307 \pm 0.803$ & $52.142 \pm 1.374$ & $96.208 \pm 0.689$ & $38.933 \pm 0.770$ \\
\hline Panax ginseng C. A. Mey & $9.791 \pm 0.098$ & $58.124 \pm 1.453$ & $5.624 \pm 1.990$ & $6.652 \pm 0.169$ & $16.853 \pm 0.348$ \\
\hline Panax notoginseng (Burk.) F. H. Chen & $8.119 \pm 0.564$ & $66.308 \pm 1.136$ & $7.724 \pm 1.940$ & $1.200 \pm 0.037$ & $11.115 \pm 0.109$ \\
\hline Papaver rhoeas L. & $17.037 \pm 0.155$ & $39.337 \pm 1.248$ & $14.824 \pm 1.272$ & $4.878 \pm 0.369$ & $47.680 \pm 1.029$ \\
\hline Prunus persica (L.) Batsch & $35.999 \pm 0.827$ & $60.335 \pm 1.262$ & $27.926 \pm 1.736$ & $20.713 \pm 0.718$ & $60.139 \pm 0.884$ \\
\hline Rosa rugosa Thunb. & $94.244 \pm 0.163$ & $88.560 \pm 0.277$ & $57.321 \pm 0.608$ & $92.164 \pm 0.799$ & $77.312 \pm 0.732$ \\
\hline Tagetes erecta $\mathrm{L}$. & $17.150 \pm 0.813$ & $48.059 \pm 0.680$ & $19.847 \pm 1.246$ & $14.139 \pm 0.369$ & $42.453 \pm 0.845$ \\
\hline Trollius chinensis Bunge & $66.152 \pm 0.952$ & $78.554 \pm 1.176$ & $38.884 \pm 0.376$ & $18.626 \pm 0.293$ & $83.797 \pm 0.884$ \\
\hline Black tea P.E. Camellia sinensis & $85.322 \pm 1.019$ & $92.204 \pm 0.253$ & $48.139 \pm 0.534$ & $60.704 \pm 1.233$ & $60.288 \pm 1.694$ \\
\hline Green tea P.E. Camellia sinensis & $93.191 \pm 0.815$ & $78.047 \pm 1.847$ & $59.169 \pm 1.571$ & $88.356 \pm 1.489$ & $26.667 \pm 0.732$ \\
\hline
\end{tabular}

${ }^{\mathrm{a}} \mathrm{FRSA}=$ Free radical scavenging activity, $\mathrm{PC}=$ Polyphenolic content, $\mathrm{FC}=$ Flavonoid content. The mean values were obtained from triplicate experiments, the concentration of extracts were $1 \mathrm{mg} / \mathrm{ml}$. 


\section{Hydroxyl radical scavenging assay}

The hydroxyl FRSA was assayed by using the 1,10-phenanthroline- $\mathrm{Fe}^{2+}$ oxidative method (Jin et al. 1996). The reaction mixture contained $0.15 \mathrm{ml}$ of $5 \mathrm{mM}$ 2-deoxyribose, $0.4 \mathrm{ml}$ of $0.75 \mathrm{M}$ sodium phosphate buffer solution (PBS, $\mathrm{pH} 7.4), 0.25 \mathrm{ml}$ of $\mathrm{H}_{2} \mathrm{O}, 0.1 \mathrm{ml}$ of $7.5 \mathrm{mM} \mathrm{FeSO}_{4}, 0.1 \mathrm{ml}$ of $1 \% \mathrm{H}_{2} \mathrm{O}_{2}$ and $0.1 \mathrm{ml}$ of sample solution. The reaction was started by the addition of $\mathrm{H}_{2} \mathrm{O}_{2}$. After incubation at $37^{\circ} \mathrm{C}$ for $1 \mathrm{~h}$, the absorbance of solution was measured at $536 \mathrm{~nm}$. Hydroxyl FRSA was evaluated as the inhibition rate of 1,10 -phenanthroline- $\mathrm{Fe}^{2+}$ oxidation by hydroxyl radical. The FRSA was calculated using the following equation:

$$
\operatorname{FRSA}(\%)=\left(\mathrm{A}_{\text {sample }}-\mathrm{A}_{\text {control }}\right) /\left(\mathrm{A}_{\text {blank }}-\mathrm{A}_{\text {control }}\right) \times 100
$$

Where, $A_{\text {sample }}$ is the absorbance in the presence of sample and $\mathrm{H}_{2} \mathrm{O}_{2} ; \mathrm{A}_{\text {control }}$ is the absorbance in the presence of $\mathrm{H}_{2} \mathrm{O}_{2}$ without sample; $\mathrm{A}_{\text {blank }}$ is the absorbance without sample and $\mathrm{H}_{2} \mathrm{O}_{2}$. Each assay was performed in triplicate.

\section{Superoxide radical scavenging assay}

The superoxide FRSA was evaluated by the method of Zhishen et al. (1999) with some variations. The system contained $2.4 \mathrm{ml}$ of $62.5 \mathrm{mM}$ sodium phosphate buffer (pH 7.8), $0.2 \mathrm{ml}$ of $0.06 \mathrm{mM}$ riboflavin, $0.1 \mathrm{ml}$ of $0.003 \mathrm{mM}$ ethylenediaminetetracetic acid disodium salt (EDTA), $0.2 \mathrm{ml}$ of $1.125 \mathrm{mM}$ nitroblue tetrazolium (NBT) and $0.05 \mathrm{ml}$ of sample solution. The photoinduced reactions were performed in an aluminium foillined box with fluorescent lamps. The distance between the reactant and the lamp was adjusted until the intensity of illumination reached about $4000 \mathrm{~lx}$. The reactant was illuminated at $25^{\circ} \mathrm{C}$ for $25 \mathrm{~min}$. The photochemicallyreduced riboflavin generated superoxide radical which reduced NBT to form blue formazan. Illuminated reaction mixture without a sample was used as a control. The reaction mixture was measured at $560 \mathrm{~nm}$. The FRSA was calculated using the following equation:

$$
\operatorname{FRSA}(\%)=\left[\left(\mathrm{A}_{\text {control }}-\mathrm{A}_{\text {sample }}\right) / \mathrm{A}_{\text {control }}\right] \times 100
$$

Each assay was performed in triplicate.

\section{Determination of the content of polyphenolics}

The polyphenolic contents were measured by the method of $\mathrm{He}$ and Zhang (1998). In a screw-capped tube, $4 \mathrm{ml}$ of $\mathrm{H}_{2} \mathrm{O}$ and $5 \mathrm{ml}$ of ferrous tartrate were added. Then $1 \mathrm{ml}$ of aqueous extract and $15 \mathrm{ml}$ of phosphate buffer ( $\mathrm{pH} 7.5$, $0.1 \mathrm{M}$ ) were added to give a total volume of $25 \mathrm{ml}$. The absorbance was measured at $540 \mathrm{~nm}$. Results were expressed as mg catechin equivalents (CE) per gram dry weight. Each assay was performed in triplicate.

\section{Determination of the content of flavonoids}

The spectrophotometer assay for the quantitative determination of flavonoid content was carried out as described by Zhishen et al. (1999). Briefly, the extract was diluted with $4 \mathrm{ml}$ distilled water. At zero time, $0.3 \mathrm{ml} 5 \%$ $\mathrm{NaNO}_{2}$ was added to the mixture. After $5 \mathrm{~min}, 3 \mathrm{ml}$ $10 \% \mathrm{AlCl}_{3}$ was added. After another $6 \mathrm{~min}, 2 \mathrm{ml} 1 \mathrm{M}$ $\mathrm{NaOH}$ was added and the total volume was made up to $10 \mathrm{ml}$ with distilled water. Immediately, the solution was mixed well again and the absorbance of the mixture, pink in colour, was determined at $510 \mathrm{~nm}$ versus prepared water blank. Total flavonoids were expressed on a weight basis as $\mathrm{mg}$ catechin equivalents (CE) per gram dry weight. Each assay was performed in triplicate.

\section{Statistical analysis}

Statistical analyses were performed according to the SPSS (version 11.5). Pearson's correlation analysis was used to test for the significance of relationship. Values expressed were obtained from three independent experiments and averaged.

\section{Results}

\section{Comparison of DPPH, hydroxyl, and superoxide radical} scavenging activities

The scavenging activities of extracts from various flower materials on three free radicals, expressed as FRSA (\%), were listed in Table 1.

Results showed that DPPH FRSA ranged from $8.119 \pm$ 0.564\% (Panax notoginseng (Burk.) F. H. Chen) to $94.244 \pm$ 0.163\% (Rosa rugosa Thunb), black tea was $85.322 \pm 1.019 \%$, and green tea was $93.191 \pm 0.815 \%$. R. rugosa Thunb, Paeonia suffruticosa Andr., Paeonia lactiflora Pall., Trollius chinenses Bunge, Osmanthus fragrans (Thunb.) Lour., Lonicera japonica Thunb. showed higher FRSA (>50\%) when compared with other extracts.

The scavenging activity of extracts on superoxide radical fluctuated between $0.405 \pm 0.268 \%$ (Jasminum sambac (L.) Ait.) and $58.420 \pm 0.842 \%$ (O. fragrans (Thunb.) Lour.), black tea was $48.139 \pm 0.534 \%$, and green tea was $59.169 \pm 1.571 \%$. O. fragrans (Thunb.) Lour. possessed the highest FRSA, followed by $R$. rugosa Thunb, P. lactiflora Pall., P. suffruticosa Andr. (>50\%).

The reducing power of hydroxyl FRSA ranged from $33.513 \pm 0.844 \%$ (Chrysanthemum morifolium Ramat) to $93.220 \pm 0.346 \%$ (Hibiscus sabdariffa Linn.), black tea was $92.204 \pm 0.253 \%$, and green tea was $78.047 \pm 1.847 \%$. $H$. sabdariffa Linn. was found to have the highest FRSA, followed by $P$. suffruticosa Andr., $R$. rugosa Thunb., $P$. lactiflora Pall., Lilium longiflorum Thumb. (>80\%).

\section{Polyphenolic and flavonoid contents}

The total polyphenolic contents of the tested materials varied from $1.070 \pm 0.148 \mathrm{mg} \mathrm{CE} / \mathrm{g}$ (L. longiflorum Thumb.) to 
$96.208 \pm 0.689 \mathrm{mg} \mathrm{CE} / \mathrm{g}$ (P. suffruticosa Andr.) (Table 1), black tea was $60.704 \pm 1.233 \mathrm{mg} \mathrm{CE} / \mathrm{g}$, and green tea was $88.356 \pm 1.489 \mathrm{mg} \mathrm{CE} / \mathrm{g}$.

The total flavonoid contents of the tested materials varied from $10.837 \pm 0.336 \mathrm{mg} \mathrm{CE} / \mathrm{g} \mathrm{C}$. morifolium Ramat) to $83.797 \pm 0.884 \mathrm{mg} \mathrm{CE} / \mathrm{g}$ (Trollius chinensis Bunge) (Table 1), black tea was $60.288 \pm 1.694 \mathrm{mg} \mathrm{CE} / \mathrm{g}$, and green tea was $26.667 \pm 0.732 \mathrm{mg} \mathrm{CE} / \mathrm{g}$.

As observed from above results, 19 edible herbal flowers tested in this study exhibited antioxidant activities. P. suffruticosa Andr., P. lactiflora Pall., and R. rugosa Thunb. had obviously stronger FRSA activity and polyphenolic contents that were superior or comparable to black and green teas (Table 1). Our results were agreed with those observed by (Li et al. 2008, 2014) who also found those herbs had significant antioxidant properties and phenolic contents.

Polyphenolic content was found to be statistically significant with DPPH FRSA $(r=0.943, P<0.01)$, superoxide FRSA $(r=0.833, P<0.01)$, and hydroxyl FRSA $(r=0.500$, $P<0.05)$. In addition, a significant relation was also detected between DPPH and superoxide FRSA $(r=0.897$, $P<0.01)$, DPPH and hydroxyl FRSA $(r=0.555, P<0.01)$, superoxide and hydroxyl FRSA $(r=0.486, P<0.05)$ (Table 2). It suggested that phenolic compounds were largely responsible for total antioxidant capacity of the tested samples. The results were similar to previous reports that phenolic compounds were major antioxidant constituents in medicinal herbs, vegetables, fruits and spices (Cai et al. 2004; Huang et al. 2010; Li et al. 2013). However, there was no significant correlation between flavonoid contents and three tested free radicals (Table 2). Miliauskas et al. also reported that phenolic compounds were likely to contribute to the FRSA, and flavonoids showed only low correlation with FRSA and total amount of phenolics (Miliauskas et al. 2004).

Herbal flowers used in the test are often consumed in the form of teas. Herbal teas have been gaining popularity in western countries in recent years (Manteiga et al. 1997). Hundreds of different herbal teas are sold in health food stores. Available as pure or blended samples, herbal teas are popular because of their fragrance, antioxidant properties and therapeutic applications (Naithani et al. 2006). Chrysanthemum indicum L. has a long history for the treatment of inflammation, hypertension and respiratory diseases in China (Cheng et al. 2005). Flowers of Chrysanthemum morifolium Ramat are used as a Chinese natural medicine. Florists Chrysanthemum Flower (Ju Hua) is prescribed for anti-inflammatory, analgesic, and antipyretic purposes (Duh 1999). Hibiscus sabdariffa Linn. flowers are potentially a good source of antioxidant agents as anthocyanins (Ali et al. 2003). The roots of Paeonia lactiflora Pall. are commonly used in traditional Chinese medicine which showed to possess antispasmodic, antiinflammatory and analgesic effects (Lee et al. 2005). Recent studies indicated that the extracts of Paeonia lactiflora Pall. flowers were also rich of polyphenols (Shu et al. 2014). The flowers of Paeonia suffruticosa Andr. are used in Chinese folk medicines for the treatment of diseases related mainly to irregular menstruation and dysmenorrhea (Huang 1994). Flowers and buds of Lonicera japonica Thumb., commonly known as Jinyinhua in traditional Chinese medicines, has been used for the treatment of affection by exopathogenic wind-heat or epidemic febrile disease at the early stage, sores, carbuncles, furuncles and swellings for centuries (Peng et al. 2005). Osmanthus fragrans (Oleaceae), also known as sweet olive, is a flower native to China, which is valued as an additive for tea and other beverages (Lee et al. 2007). Dried petals of Rosa rugosa Thunb. have been widely used as main material in preparation of rose teas in China, which was believed to provide nourishment and favor human health (Vinokur et al. 2006). Tea from Camellia sinensis, used as positive control in the test, is the most widely consumed beverage in the world, and it is an important dietary source of natural phenolic antioxidants (Lachman et al. 2003).

Table 2 Correlation analysis between polyphenolic content, flavonoid content and three free radicals

\begin{tabular}{|c|c|c|c|c|c|c|}
\hline & & DPPH FRSA & Hydroxyl FRSA & Superoxide FRSA & Polyphenolic content & Flavonoid content \\
\hline \multirow[t]{2}{*}{ DPPH FRSA } & Pearson Correlation & 1 & & & & \\
\hline & Sig. (2-tailed) & . & & & & \\
\hline \multirow[t]{2}{*}{ Hydroxyl FRSA } & Pearson Correlation & $.555\left({ }^{* *}\right)$ & 1 & & & \\
\hline & Sig. (2-tailed) & .009 & . & & & \\
\hline \multirow[t]{2}{*}{ Superoxide FRSA } & Pearson Correlation & $.897\left(^{* *}\right)$ & $.486\left(^{*}\right)$ & 1 & & \\
\hline & Sig. (2-tailed) & .000 & .026 & . & & \\
\hline \multirow[t]{2}{*}{ Polyphenolic content } & Pearson Correlation & $.943(* *)$ & $.500\left(^{*}\right)$ & $\left..8377^{* *}\right)$ & 1 & \\
\hline & Sig. (2-tailed) & .000 & .021 & .000 & & \\
\hline \multirow[t]{2}{*}{ Flavonoid content } & Pearson Correlation & .328 & .217 & .227 & .194 & 1 \\
\hline & Sig. (2-tailed) & .147 & .345 & .322 & .400 & . \\
\hline
\end{tabular}

**Correlation is significant at the 0.01 level (2-tailed); ${ }^{*}$ Correlation is significant at the 0.05 level (2-tailed). 


\section{Conclusion}

In conclusion, The 19 edible flowers used in this study were carried as edible herbal tea resources and had been currently in commercial production in China. It was clearly demonstrated Paeonia suffruticosa Andr., Paeonia lactiflora Pall., and Rosa rugosa Thunb. had obviously stronger antioxidant activity and polyphenolic contents that were superior or comparable to black and green teas. Polyphenolic contents did correlate well with DPPH, superoxide, and hydroxyl FRSA. However, flavonoid contents did not correlate well with those FRSA. These findings can form the basis for further studies to isolate active compounds, and may contribute greatly to diversify and enhance the health-maintaining properties of the daily diet. However, in vivo studies are needed to confirm the health-promoting potential of these herbs.

\section{Competing interests}

The authors declare that they have no competing interests.

\section{Authors' contribution}

ZYW design the experiment, carried out the experiment, and drafted the manuscript. DMC and LZC design the experiment. PYH supervised the work. All authors read and approved the final manuscript.

\section{Acknowledgements}

This work was financially supported by the grants from Natural Science Foundation of Guangdong Light Industry Technical College (KJ201312), Centre of Guangdong Higher Education of Engineering and Technological Development Guangdong Province of China (GCZX-B1103).

\section{Author details}

1 Department of Food and Bio-engineering, Guangdong Light Industry Technical College, Guangzhou 510300, Guangdong, China. ${ }^{2}$ Centre of Guangdong Higher Education of Engineering and Technological Development of Speciality Condiments, Guangdong Light Industry Technical College, Guangzhou 510300, Guangdong, China. ${ }^{3}$ Department of Life Science, Huizhou University, Huizhou 516007, Guangdong, China. ${ }^{4}$ College of Life Science, Guangdong Key Lab of Biotechnology for Plant Development, South China Normal University, Guangzhou 510631, Guangdong, China.

Received: 24 April 2014 Accepted: 19 June 2014

Published: 25 June 2014

\section{References}

Ali BH, Mousa HM, El-Mougy S (2003) The effect of a water extract and anthocyanins of Hibiscus sabdariffa L. on paracetamolinduced hepatoxicity in rats. Phytother Res 17:56-59

André C, Castanheira I, Cruz JM, Paseiro P, Sanches-Silva A (2010) Analytical strategies to evaluate antioxidants in food: a review. Trends Food Sci Tech 21:229-246

Aruoma Ol (1998) Free radicals, oxidative stress and antioxidants in human health and disease. J Am Oil Chem Soc 75:199-212

Balaban RS, Nemoto S, Finkel T (2005) Mitochondria, oxidants, and aging. Cell 120:483-495

Cai YZ, Luo Q, Sun M, Corke H (2004) Antioxidant activity and phenolic compounds of 112 traditional Chinese medicinal plants associated with anticancer. Life Sci 74:2157-2184

Cai YZ, Sun M, Xing J, Luo Q, Corke H (2006) Structure-radical scavenging activity relationships of phenolic compounds from traditional Chinese medicinal plants. Life Sci 78:2872-2888

Cheng W, Li J, You T, Hu C (2005) Anti-inflammatory and immunomodulatory activities of the extracts from the inflorescence of Chrysanthemum indicum Linn'e. J Ethnopharmacol 101:334-337

Duh PD (1999) Antioxidant activity of water extract of four Harng Jyur (Chrysanthemum morifolium Ramat) varieties in soybean oil emulsion. Food Chem 66:471-476
He ZF, Zhang DQ (eds) (1998) Healthy food chemistry and detection technique. China Light Industry Press, Beijing

Huang TK (ed) (1994) A handbook of the composition and pharmacology of common Chinese drugs. Press Chinese Med Tech, Beijing, p 1040

Huang WY, Cai YZ, Corke H, Sun M (2010) Survey of antioxidant capacity and nutritional quality of selected edible and medicinal fruit plants in Hong Kong. J Food Compos Anal 23:510-517

Jin M, Cai YX, Li JR (1996) 1,10-Phenanthroline-Fe ${ }^{2+}$ oxidative assay of hydroxyl radical produced by $\mathrm{H}_{2} \mathrm{O}_{2} / \mathrm{Fe}^{2+}$. Progr Biochem Biophys 23:553-555

Kris-Etherton PM, Hecker KD, Bonanome A, Coval SM, Binkoski AE, Hilpert KF, Griel $A E$, Etherton TD (2002) Bioactive compounds in foods: their role in the prevention of cardiovascular disease and cancer. Am J Med 113:71-88

Krishnaiah D, Sarbatly R, Nithyanandam R (2011) A review of the antioxidant potential of medicinal plant species. Food Bioprod Process 89:217-233

Lachman J, Orsak M, Pivec V, Dudjak J, Krym O (2003) Polyphenol content in green, black and oolong tea (Camelia sinensis (L.) Kuntze) infusions in different times of tea maceration. Scientia Agric Bohem 34:22-28

Lee SC, Kwon YS, Son KH, Kim HP, Heo MY (2005) Antioxidative constituents from Paeonia lactiflora. Arch Pharm Res 28:775-783

Lee HH, Lin CT, Yang LL (2007) Neuroprotection and free radical scavenging effects of Osmanthus fragrans. J Biomed Sci 14:819-827

Li HB, Wong CC, Cheng KW, Chen F (2008) Antioxidant properties in vitro and total phenolic contents in methanol extracts from medicinal plants. LWT - Food Sci Technol 41:385-390

Li S, Li SK, Gan RY, Song FL, Kuang L, Li HB (2013) Antioxidant capacities and total phenolic contents of infusions from 223 medicinal plants. Ind Crop Prod 51:289-298

Li AN, Li S, Li HB, Xu DP, Xu XR, Chen F (2014) Total phenolic contents and antioxidant capacities of 51 edible and wild flowers. J Funct Foods 6:319-330

Manteiga R, Park DL, Ali SS (1997) Risks associated with consumption of herbal teas. Rev Environ Contam Toxicol 150:1-30

Miliauskas G, Venskutonis PR, van Beek TA (2004) Screening of radical scavenging activity of some medicinal and aromatic plant extracts. Food Chem $85: 231-237$

Moskovitz J, Yim MB, Chock PB (2002) Free radicals and disease. Arch Biochem Biophys 397:354-359

Naithani V, Nair S, Kakkar P (2006) Decline in antioxidant capacity of Indian herbal teas during storage and its relation to phenolic content. Food Res Int 39:176-181

Peng YY, Liu F, Ye JN (2005) Determination of phenolic acids and flavones in Lonicera japonica Thumb. by capillary electrophoresis with electrochemical detection. Electroanal 17:356-362

Saeidnia S, Abdollahi M (2013) Toxicological and pharmacological concerns on oxidative stress and related diseases. Toxicol Appl Pharmacol 15:442-455

Sharma OP, Bhat TK (2009) DPPH antioxidant assay revisited. Food Chem 113:1202-1205

Shu XK, Duan WJ, Liu F, Shi XA, Geng YL, Wang X, Yang BT (2014) Preparative separation of polyphenols from the flowers of Paronia lactiflora Pall by high-speed counter-current chromatography. J Chromatogra B 947-948:62-67

Sies H (1993) Strategies of antioxidant defense. Eur J Biochem 215:213-219

Vinokur Y, Rodov V, Reznick N, Goldman G, Horev B, Umiel N, Friedman H (2006) Rose petal tea as an antioxidant-rich beverage: cultivar effects. J Food Sci $71: s 42-s 47$

Wang SP, Hu YY, Tan W, Wu X, Chen R, Cao JL, Chen MW, Wang YT (2012) Compatibility art of traditional Chinese medicine: from the perspective of herb pairs. J Ethnopharmacol 143:412-423

Williams GM, latropoulos MJ, Whysner J (1999) Safety assessment of butylated hydroxyanisole and butylated hydroxytoluene as antioxidant food additives. Food Chem Toxicol 37:1027-1038

Zhishen J, Mengcheng T, Jianming W (1999) The determination of flavonoid contents in mulberry and their scavenging effects on superoxide radicals. Food Chem 64:555-559

doi:10.1186/2193-1801-3-315

Cite this article as: Zeng et al.: Evaluation of antioxidant activities of extracts from 19 Chinese edible flowers. SpringerPlus 2014 3:315. 